\section{First lord of British science}

\section{David Gooding}

Energy and Emplre: A Blographical Study of Lord Kelvin. By Crosbie Smith and M. Norton Wise. Cambridge University Press: 1989. Pp. 866. £60, \$89.50.

BORN in Belfast in 1824 and raised and educated in Glasgow, William Thomson made important contributions to field theory, thermodynamics, electrical and navigational instrumentation and to communications, engineering the first successful trans-Atlantic cable in 1866, for which he was knighted that year. $\mathrm{He}$ was elevated to the peerage in 1892 , the first scientist to be so honoured.

Thomson took the name Kelvin from the river that flows past the University of Glasgow, where he was professor of natural philosophy from 1846 to 1899 . Such was his role in creating the new mathematical physics, based on energy, and in developing the technologies of his time, that Smith and Wise have had to write a biography of the family of disciplines and professions that made up victorian science as well as a life of Thomson. Their book is finely worked, comprehensive, well-written and fully equal to the ambitious pace and grand scale of the life of this first lord of British science. It is a model study of how personal qualities and circumstances interact with social and cultural influences to shape an individual and what he creates.

Educated first by his father and then at Glasgow College and at Cambridge University, William's future was charted by his father, for whom his appointment as professor both secured his son's future and promoted the liberal, democratic and anti-sectarian cause within Glasgow College. Smith and Wise describe the mathematical culture on which Thomson's early papers drew and to which the reforming mathematical style, typified by the new operational calculus he promoted through the Cambridge and Mathematical Journal, was a response. (They also rescue the mathematics tutor William Hopkins from undeserved neglect.)

Family correspondence shows that when a Cambridge undergraduate, William remained loyal to the values and ideals of the Thomson family. Having done brilliantly at Cambridge, he took his father's advice to travel to Paris to learn experimental methods in Regnault's laboratory. This ensured that he returned to Glasgow as a practical scotsman as well as a Cambridge mathematician. Within four years of his appointment as professor at the age of 22 , Thomson established the century's most successful applied physics laboratory, remembered for its compasses and precision instruments, but important also for another innovation: using laboratory instruction to teach experimental practice and mental habits of accuracy and precision. This was Britain's first physics teaching laboratory, harnessing the skills of a large corps of students to produce intellectual capital which he invested in new ventures.

A keen collaborator who shunned disciplinary walls, Thomson had many discussions with Faraday, Maxwell, Joule,

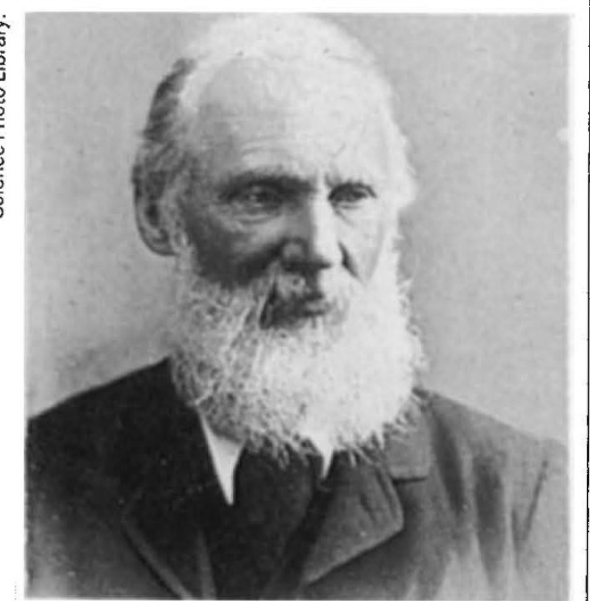

Kelvin - knowledge through measurement.

Rankine, his brother the steam-engineer James Thomson (to name a few) and with P. G. Tait, with whom he wrote the Treatise on Natural Philosophy, intended to replace the force-based mechanics of Newton's Principia by the new physics of energy. New experimental and mathematical results were as grist to an intellectual engine, driven by the need to minimize waste and extract maximum effect. Smith and Wise document a lifelong concern with efficiency and economy, and Thomson's extraordinary productivity shows how effectively his father taught him to expend his energy in highly efficient ways.

Smith's and Wise's chapters on Thomson's contributions to marine technology and telegraphy and to the mathematical framework that embraced new discoveries in electricity, magnetism and heat are the most definitive yet written. They are a valuable source for those interested in the dynamics of science, engineering and technology, showing how Thomson combined enthusiasm for Fourier's new mathematical methods with respect for Faraday's experimental work (which he had earlier despised), and how he struggled to reconcile the work of Joule and Claypeyron en route to the second law of thermodynamics. The authors' analysis of conceptual discovery includes the personal circumstances, beliefs and values that shaped Thomson's perception of wider political and economic processes, so shaping the concepts and methods he would place at the very heart of his science. They demonstrate the combined influence of the different cultures of Cambridge and of Glasgow (though their contrast understates interest in practical, useful science outside England's ancient universities) and show how the Thomson family's glaswegian perspective repeatedly drew attention to the evils of waste: William and his brother James (apprenticed to Fairburns at Millwall) noticed water running to waste through canal locks; later they brought attention to the loss of heat in marine steam engines.

From their material environment the two sons drew phenomena expressing the values inculcated by their father. Was William therefore a rude mechanic? Because he rejected Maxwell's liberation of his field equations from the mechanical models that helped articulate them, and because he assiduously paired mathematics and measurement to get to grips with work and waste, it became fashionable to treat Thomson as an object lesson in the dangers of insisting on concrete, personal experience when interpreting concepts, and of emphasizing the commercial exploitation of results. But to dismiss Thomson's science as the physics of the factory and the marketplace is too smug. Thomson never entertained a distinction between theory and practice (such as still informs much science teaching today), so it was natural to identify knowledge with measurement, as when he wrote that "When you can measure what you are speaking about ... you know something about it, and when you cannot measure it ... your knowledge is of a meagre and unsatisfactory kind ..."

Commercial success did not cause Thomson to adopt an economic view of measurement: Smith and Wise show convincingly how economics and epistemology had always been implicitly related. They also link Thomson's pursuit of uniform standards of measurement for the empire with his support of the unionist cause (he opposed the creation of an Irish state independent of Britain) to the liberal, antisectarian attitudes of his Irish origins. This argues a deep and personal connection between the name of the temperature scale and that of the peer, because Kelvin's title was a reward more for his unionist sympathies than for his scientific services to nation and empire.

Smith and Wise attend as much to the personal as to the technical and social dimensions of science, so their account should be read by anyone who wants to understand how people weave the fabric of hard science.

David Gooding is in the Science Studies Centre of the University of Bath, Claverton Down, Bath BA2 7AY, UK. 